\title{
Asistensi Penulisan Karya Tulis Ilmiah Terakreditasi Sinta
}

\author{
Hantono $^{1)}$ |Evan Afri ${ }^{2)}$ | Intan maulina ${ }^{3)}$ | Muhammad Khoiruddin Harahap ${ }^{4)}$ | \\ ${ }^{1)}$ Fakultas Ekonomi, Jurusan Akuntansi Universitas Pelita Harapan(UPH) Medan \\ 2,4) Politeknik Ganesha Medan \\ 3) Universitas Efarina \\ hantono1978@gmail.com | evanafri@gmail.com| intanmaulina1509@gmail.com | Choir.harahap@yahoo.com
}

\begin{abstract}
Abstrak: Penulisan karya tulis ilmiah merupakan keterampilan yang penting untuk dimiliki oleh akademisi, maupun mahasiswa dalam menjalani tugas akhir dimana keterampilan menulis karya ilmiah sangat diperlukan oleh akademisi, maupun mahasiswa dalam menyampaikan gagasan secara ilmiah dan bertanggung jawab. Sayangnya, tidak banyak kampus yang memahami pentingnya keterampilan menulis ilmiah dan cara melaksanakanannya dengan baik, sehingga banyak artikel kena tolak. Publikasi karya ilmiah menjadi agenda penting bagi para akademisi, bukan hanya sebagai prasyarat utk naik kepangkatan dosen dan bukan semata untuk mahasiswa S1 yang mau lulus ujian skripsi, semuanya penuh proses makanya beberapa panitia yang tergabung di dalam tim IT Science berencana untuk melakukan webinar agar mempunyai gambaran yang jelas mengenai penulisan karya tulis terakreditasi sinta sangat cocok untuk mahasiswa, dosen, penulis pemula, dimana webinar ini dilakukan dengan mengkolaborasikan 3 pembicara yang sesuai dengan keahlian masing masing seperti Prof.Dr.Muhammad Zarlis (Penguatan Substansi Karya Ilmiah), Nurul Khairina, S.Kom, M.Kom (Optimalisasi Grammarly, google translate \&Paraphrasing) dan Paska MartoHasugian, S.Kom, M.Kom (Asistensi Penulisan Karya Ilmiah). Kegiatan ini merupakan bagian dari kegiatan pengabdian masyarakat yang bertujuan untuk memberikan tambahan ilmu pengetahuan, meningkatkan keterampilan, memudahkan peserta untuk menentukan asistensi artikel sampai terbit di Jurnal Nasional Terakreditasi Sinta.
\end{abstract}

Kata Kunci: Karya Ilmiah, Optimalisasi Grammarly,Mendeley

\section{Pendahuluan}

Menulis karya ilmiah merupakan salah satu bentuk keterampilan yang penting dalam dunia pendidikan. Hampir seluruh Pendidikan Tinggi di dunia mengharuskan lulusannya untuk dapat mampu menghasilkan karya tulis ilmiah. Menulis karya tulis ilmiah adalah keterampilan yang tidak dapat muncul dengan alami seperti mendengar dan berbicara. Menulis karya ilmiah adalah keterampilan yang perlu dipelajari, dilatih dan dikembangkan (Kalidjernih, 2010). Oleh sebab itu, adalah hal yang wajar jika banyak yang merasa kesulitan membuat karya tulis ilmiah karena tidak melatih diri sebelumnya. Selain itu seorang penulis karya ilmiah akan mencari suatu referensi yang didapat dari beberapa cara seperti mereka dapat mengakses internet maupun dengan membaca buku yang telah didapat tetapi masih saja banyak orang yang membuat berbagai kesalahan yaitu dengan melakukan penjiplakan karya dari suatu sumber. Penjiplakan ini yang disebut dengan plagiarisme (Rohman, 2018). Perlu diketahui bahwa kategori publikasi ilmiah dipublikasikan beberapa jenis jurnal ilmiah sepertilokal, nasional, atau internasional. Jurnal ilmiah lokal merupakan jurnal kampus, jurnal untuk himpunan mahasiswa, dan jurnal terkait perpustakaan daerah. Jurnal ilmiah tingkat nasional yaitu jurnal dipublikasikan secara nasional dan memiliki reputasi terindeks nasional yang terakreditasi maupun tidak terakreditasi(Adiyati \& Supriyanto,2020). Apalagi saat ini majunya akses teknologi akan dapat mempermudah dosen melakukan publikasi ilmiah. Penggunaanakun dan melakukan submit serta mendowload referensi yang open access yang membantu serta memberikan kemudahan para dosen, dan peneliti, serta mahasiswa. 
Dedikasi Sains dan Teknologi

Jurnal Pengabdian Masyarakat

Vol: 1, No: 2, Nopember 2021

Doi : https $/ /$ doi.org/10.47709/ dst/v1i2.1188
Diajukan : 20 Nopember 2021

Diterima : 20 Nopember 2021

Dipublikasikan : 20 Nopember 2021

Ribuan karya ilmiah dalam bentuk seperti skripsi, tesis, disertasi, maupun artikel jurnal ilmiah, prosiding seminar dapat diakses dalam waktu cepat. Sehingga kondisi sekarang dapat dikatakan seseorang akan melaksanakan penelitian tidak lagi untuk mencari sumber referensi secara manual di perpustakaan yang membutuhkan waktu relatif lama(Ginanjar, 2018).

Nah dari beberapa masalah inilah yang diperoleh oleh Tim IT Science, sehingga mempunyai ide melakukan kegiatan webinar dengan mengundang pembicara yang menguasai bidang karya ilmiah, paraphase untuk mencegah tingginya persentase plagiat serta bagaimana melakukan sitasi menggunakan mendeley.

\section{Realisasi Kegiatan}

Kegiatan Webinar ini dilaksanakan pada tanggal 6 November 2021 pukul 09.00 WIB hingga selesai dimana kegiatan ini dilakukan promo melalui penyebaran brosur di grup Whatsaap masing masing tim IT Science dan pendaftaran kegiatan ini sudah dilakukan sebelum tanggal 6 November 2021, setelah tercapai peserta maka pendaftaran ditutup. Peserta yang sudah mendaftar ada sekitar 82 peserta dari kalangan dosen, mahasiswa/i.

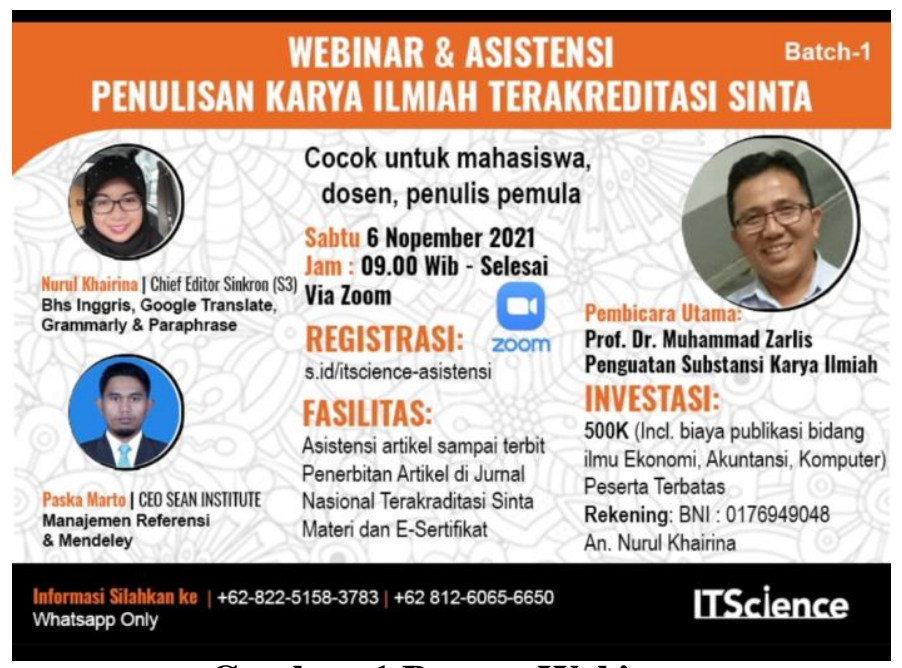

Gambar 1 Brosur Webinar

Peserta Webinar dan Asistensi yang sudah mendaftar di google form yang sudah disebarkan linknya dari pihak panitia diperoleh datanya yang terdiri dari 45 dosen S2 dan S3 dari beberapa jurusan antara lain komputer, ekonomi, akuntansi dan Manajemen yang berasal dari beberapa Universitas di luar Medan seperti UNPAD, Universitas 45 Mataram, USM Banda Aceh, Universitas Widya Gama Mahakam Samarinda, Universitas Putera Batam, Institut Teknologi Telkom Purwokerto, Universitas karyadarma kupang, UPI YPTK Padang, Politeknik Negeri Fakfak dan masih banyak lainnya. Begitu juga pesertanya yang berasal dari Mahasiswa berjumlah 31 peserta dari beberapa jurusan antara lain jurusan komputer, ekonomi, akuntansi dan Manajemen yang berasal dari kampus yang ada di Kota Medan dan juga di luar kota Medan seperti Institut Bisnis dan Informatika Kwik Kian Gie, Institut Teknologi Telkom Purwokerto, Universitas Internasional Batam, Universitas Stikubank (UNISBANK) Semarang, Sekolah Tinggi Teknologi Wastukancana dan lainnya.

Pihak Panitia telah menyusun agenda acara untuk kegiatan pelaksanaan Webinar dan Asistensi agar kegiatan dapat berjalan dengan baik dan sesuai yang direncanakan dan berikut tampilan susunan acara yang sudah disusun pada tabel berikut : 
Dedikasi Sains dan Teknologi

Jurnal Pengabdian Masyarakat

Vol: 1, No: 2, Nopember 2021

Doi : https $/ /$ doi.org/10.47709/ dst/v1i2.1188
Diajukan : 20 Nopember 2021

Diterima : 20 Nopember 2021

Dipublikasikan : 20 Nopember 2021

Tabel 1

Susunan Acara

\begin{tabular}{|c|c|c|c|}
\hline No & Pukul (WIB) & Agenda Acara & Pelaksana \\
\hline 1 & $08.30-09.00$ & Registrasi & Panitia Webinar \\
\hline 2 & $09.00-09.05$ & Pembukaan Webinar & $\begin{array}{c}\text { MC } \\
\text { Evan Afri }\end{array}$ \\
\hline \multirow{2}{*}{3} & $09.05-09.10$ & Menyanyikan Lagu Indonesia Raya & Peserta Webinar \\
\cline { 2 - 5 } & $09.10-09.15$ & Doa & $\begin{array}{c}\text { Evan Afri, S.Pd,I, } \\
\text { MS }\end{array}$ \\
\hline 4 & $09.15-10.15$ & $\begin{array}{c}\text { Presentasi Pembicara Utama dan Tanya Jawab } \\
\text { Penguatan Substansi Karya Ilmiah } \\
\text { Prof. Dr. Muhammad Zarlis }\end{array}$ & Hantono \\
\hline 5 & $10.15-11.15$ & $\begin{array}{c}\text { PresentasiPembicara dan Tanya Jawab } \\
\text { Bahasaris, Google Translate, Grammarly, } \\
\text { Paraphrase }\end{array}$ & $\begin{array}{c}\text { Intan Maulina, } \\
\text { S.Pd, MS }\end{array}$ \\
\hline 6 & $11.15-12.15$ & $\begin{array}{c}\text { Presentasi Pembicara dan Tanya Jawab } \\
\text { Manajemen Referensi dan Mendeley } \\
\text { Paska Marto Has ugian, S.Kom, M.Kom }\end{array}$ & Jonson Manurung \\
\hline 7 & $11.15-12.15$ & Penutup & MC \\
\hline
\end{tabular}

Kegiatan diawali dengan menyanyikan lagu Indonesia Raya yang diarahkan oleh moderator dan peserta mengambil sikap sempurna, setelah itu pembukaan dari Ketua Panitia yang dilanjutkan dengan doa.

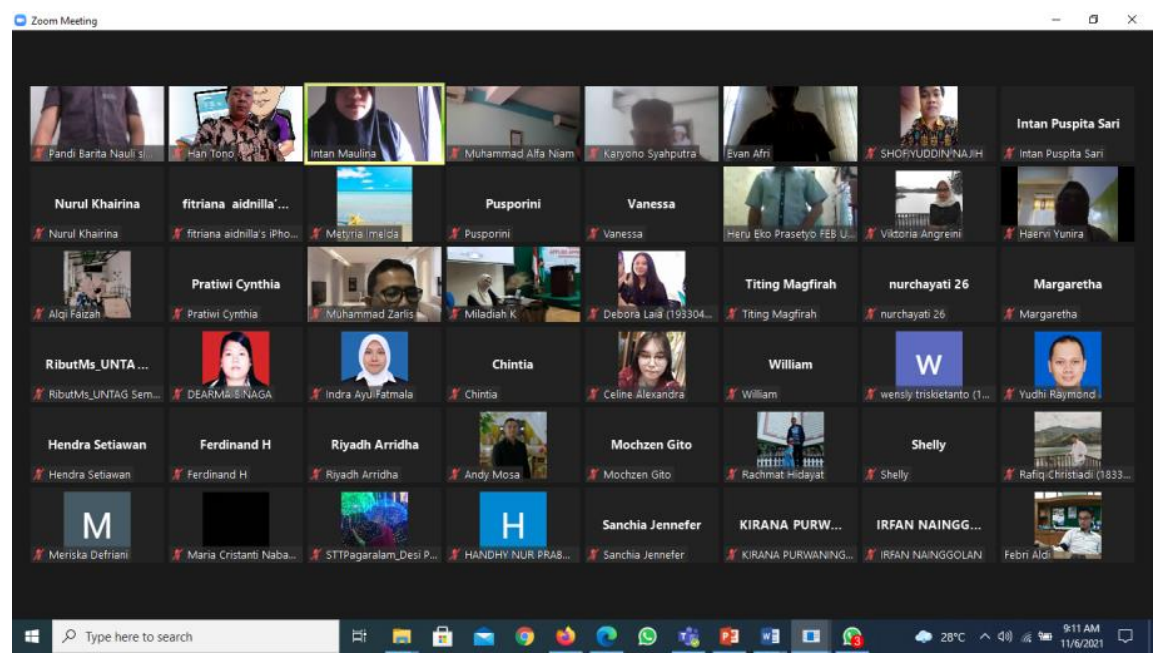

Gambar 2 Menyanyikan lagu Indonesia Raya 
Dedikasi Sains dan Teknologi

Jurnal Pengabdian Masyarakat

Vol: 1, No: 2, Nopember 2021

Doi : https $/ /$ doi.org/10.47709/ dst/v1i2.1188
Diajukan : 20 Nopember 2021

Diterima : 20 Nopember 2021

Dipublikasikan : 20 Nopember 2021

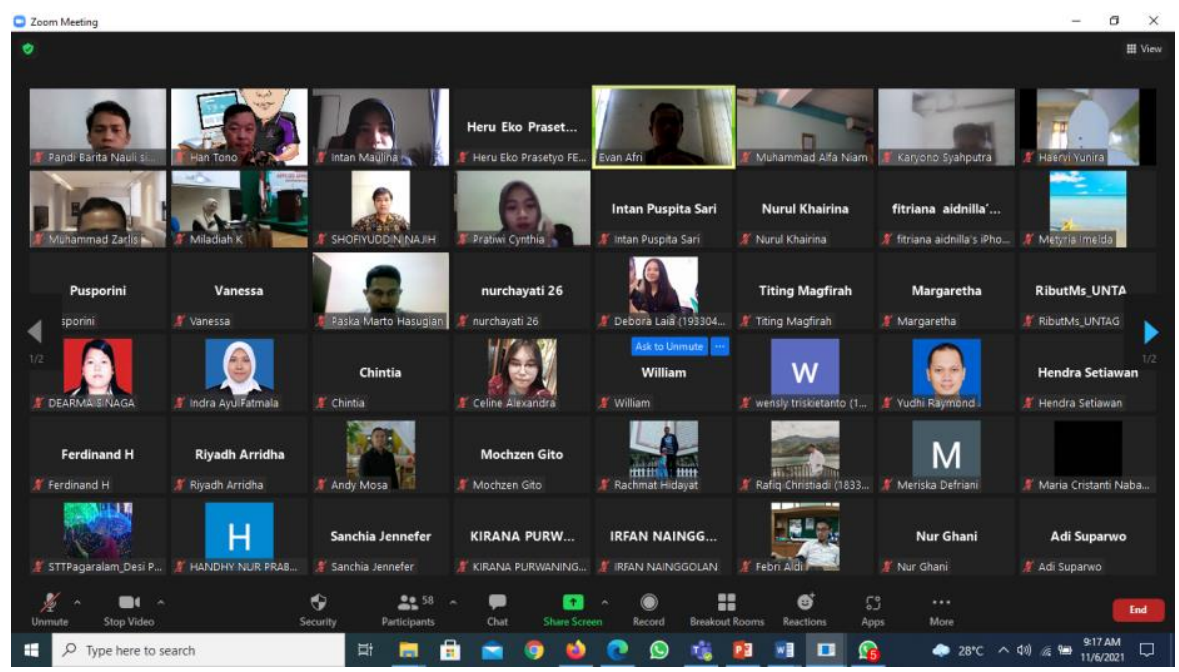

Gambar 2 Laporan Ketua Panitia sekaligus Membuka Kegiatan dan dilanjutkan Doa

Setelah selesai dilanjutkan pemaparan materi dari Pemateri Pertama yaitu Prof.Dr. Muhammad Zarlis mengenai Penguatan Substansi Karya Ilmiah

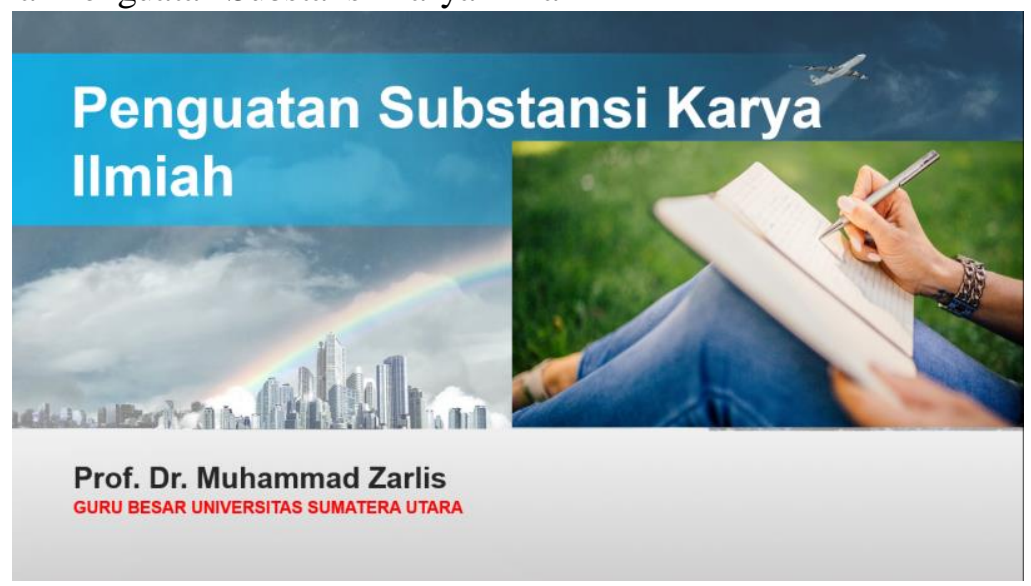


Dedikasi Sains dan Teknologi

Jurnal Pengabdian Masyarakat

Vol: 1, No: 2, Nopember 2021

Doi : https//doi.org/10.47709/ dst/vli2.1188
Diajukan : 20 Nopember 2021

Diterima : 20 Nopember 2021

Dipublikasikan : 20 Nopember 2021
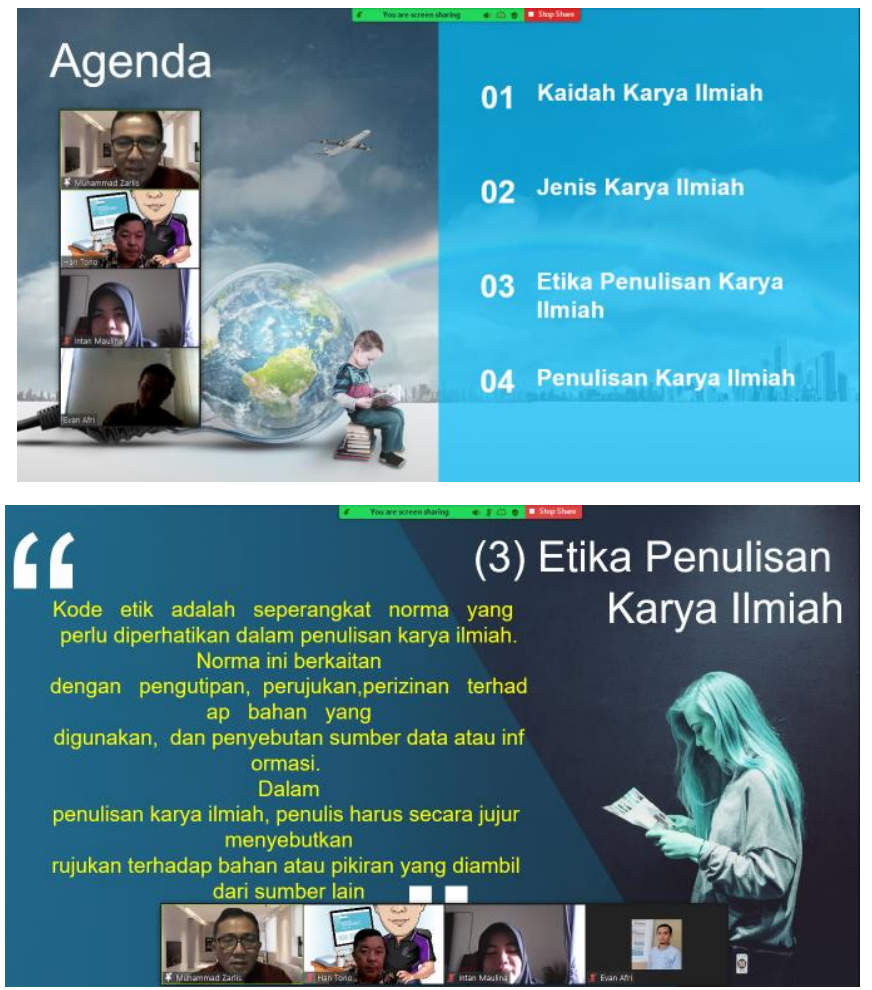

Basic Journal Publishing Standards

Citation for Engineering, Science \& Technology

- ISI Thomson - Science Citation Index (SCI, SCI Expanded)

- Scopus

- Current Contents (Engineering, Computing, Technology)

- Cambridge Scientific Abstracts

- Computer Abstracts UK, CompuSci

- Mathematics Review USA

- Mathematics Abstracts Germany

- DBLP Bibliography

- INSPEC

- Google Scholar

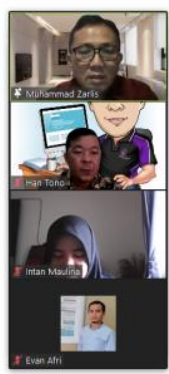

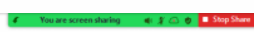

UNSUR-UNSUR PROPOSAL PENELITIAN

1. Judul

2. Latar belakang \& perumusan permasalahan (\& keaslian penelitian, dan manfaat yang dapat diharapkan)

3. Tujuan dan Lingkup penelitian

4. Tinjauan Pustaka/Landasan Teori

5. Hipotesis

6. Cara penelitian

7. Jadwal penelitian

8. Daftar Pustaka

9. Lampiran

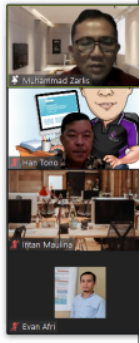

Gambar 3 Pemate ri Pertama, Prof. Dr. Muhammad Zarlis

Setelah itu dilanjutkan pemaparan dari pemateri kedua yaitu Nurul Khairina, S.Kom, M.Kom yang membahas optimalisasi grammarly, google translate dan paraphrasing.
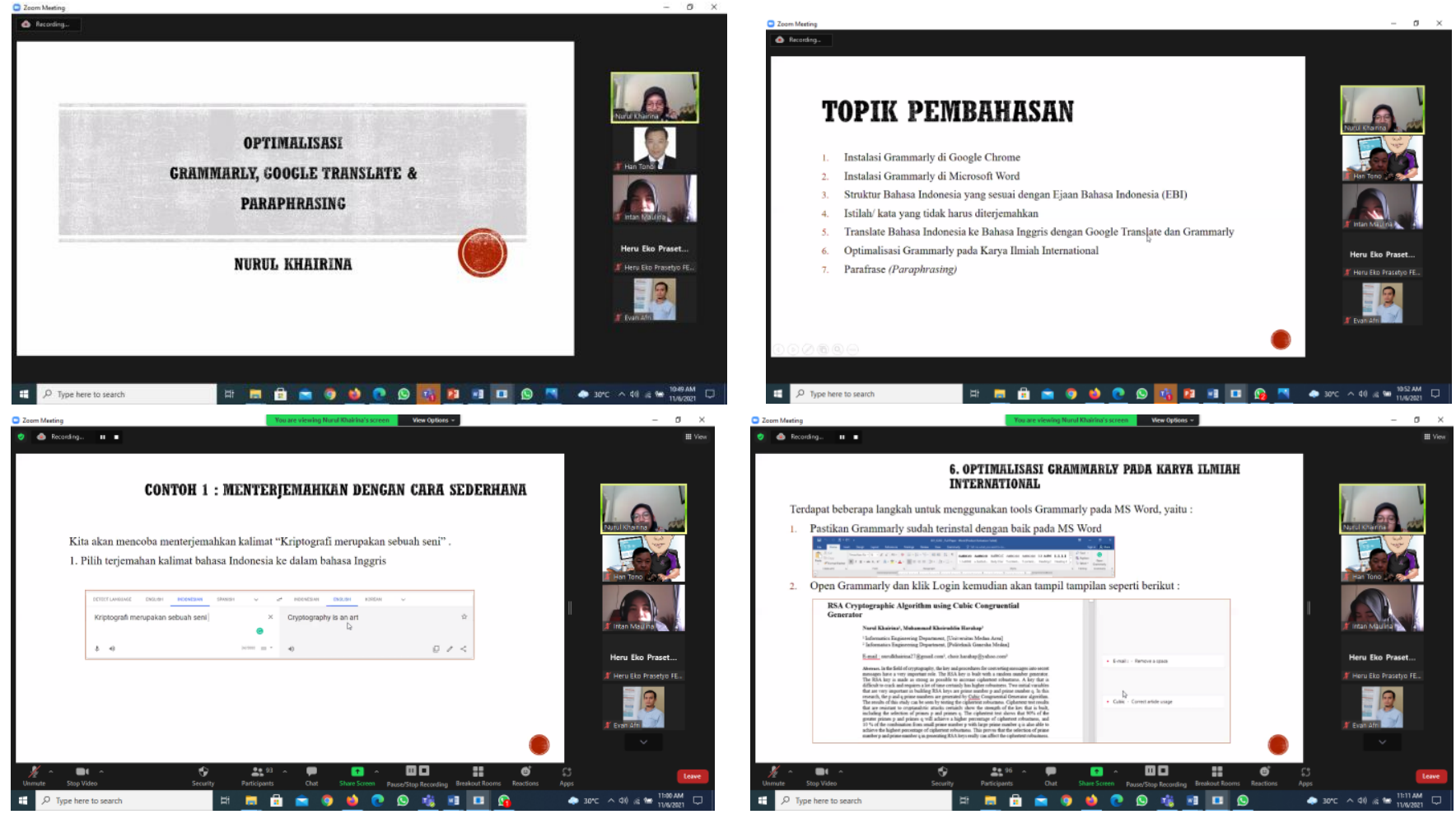

Gambar 4 Pe materi Kedua, Nurul Khairina, S.Kom, M.Kom 
Dedikasi Sains dan Teknologi

Jurnal Pengabdian Masyarakat

Vol: 1, No: 2, Nopember 2021

Doi : https $/ /$ doi.org/10.47709/ dst/v1i2.1188
Diajukan : 20 Nopember 2021

Diterima : 20 Nopember 2021

Dipublikasikan : 20 Nopember 2021

Pada pemateri ketiga yaitu Paska Marto Hasugian, S.Kom, M.Kom yang menyampaikan materi mengenai Penguatan Substansi Paper
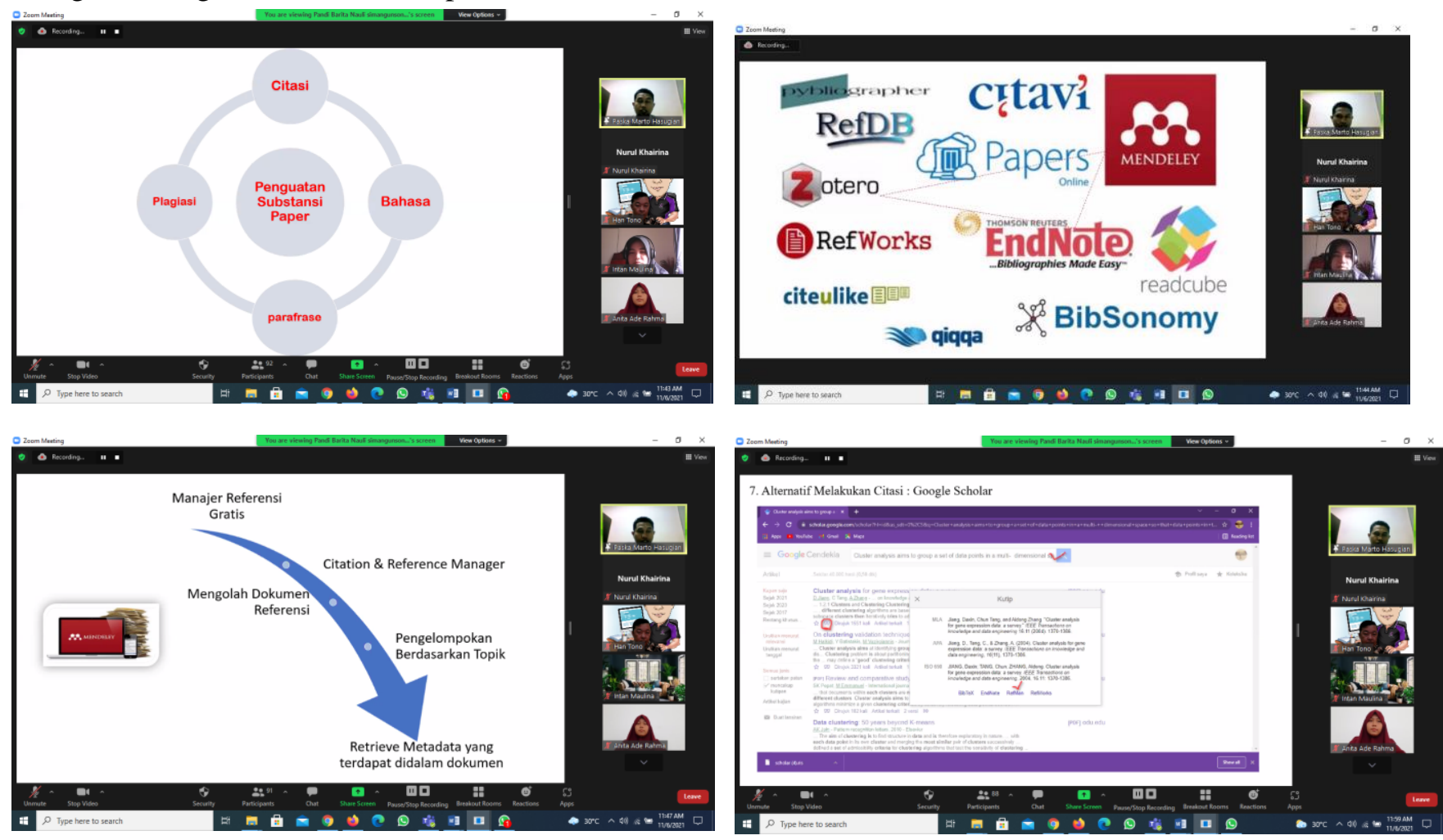

Gambar 5 Pemate ri Ketiga, Paska Marto Hasugian, S.Kom, M.Kom

\section{Hasil}

Hasil kegiatan webinar dan asistensi yang dilaksanakan adalah untuk menambah wawasan rekan - rekan dosen, mahasiswa dalam penulisan karya ilmiah mulai dari cara - cara penulisan, pengutipan hingga melakukan parapharase sudah dijabarkan dengan baik dari para pemateri yang sudah diundang sebagai pembicara

\section{Kesimpulan}

Kegiatan webinar dan asistensi dapat terlaksana dengan baik dan tujuan dilaksanakan kegiatan ini untuk meningkatkan pemahaman peserta mengenai penguatan substansi karya ilmiah, optimalisasi grammarly,google translate dan parapharase dan Penguatan Substansi Paper dengan Mendeley. Semua peserta pelatihan antusias dan merasakan manfaat webinar ini.

\section{$\underline{\text { Daftar Pustaka }}$}

Rohman, F., 2018. Peran Pendidik Dalam Pembinaan Disiplin Siswa di Sekolah / Madrash

Adiyati, G. C., \& Supriyanto, A. (2020). Penyebab Dan Dampak Bagi Seseorang Yang Melakukan

Tindakan Plagiarisme Dalam Penulisan Karya Ilmiah. Seminar Nasional-Jurusan Administrasi Pendidikan Fakultas Ilmu Pendidikan Universitas Negeri Malang, 62-70. http $/ /$ conference.um.ac.id/index.php/apfip/article/view/375.

Ginanjar, A. (2018). Peningkatan Mutu Karya Tulis Dosen Fis Dengan Menggunakan Reference Manager Software Mendeley. Harmony, 3(2), 199-203. 